https://doi.org/10.48009/1_iis_2008_196-202

\title{
PREPARING THE KNOWLEDGE WORKER: HOW CAN IS PROGRAMS MEET THE CHALLENGE?
}

\author{
Dr. Hala Annabi - Ohio University MIS Department - annabi@ohio.edu \\ Dr. Sean McGann - Ohio University MIS Department - Mcgann@Ohio.Edu
}

\begin{abstract}
Information Systems across the world are challenged by the demand of a complex and ever changing global business environment. This business environment demands "self-regenerating" professionals who are able to address socio-technical problems in a complex business context. In this paper, we propose that IS programs adopt a constructivist philosophy in their curriculum to change the way students think and develop professionals who are more adept at learning and solving real world problems. The paper outlines the elements of constructivist pedagogy and provides suggestions to how IS curriculum can implement elements of such an education philosophy.
\end{abstract}

\section{INTRODUCTION}

The business environment is more complex and turbulent than ever due to global markets, regulation, technology, shorter product life cycles and a diverse workforce. To survive and succeed in this environment an organization must learn. The more adept an organization is at learning, the better it is at adapting to its environment, avoiding stability traps, experimenting, rethinking means and ends, correcting for error, innovating, realizing human potential for learning in the service of organizational purposes, and creating organizational settings as contexts for human development (Argyris and Schön 1996). Organizations learn by integrating the knowledge of its members into rules, processes, routines, and culture (Grant 1996; Annabi 2005). According to Simon (1991), an organization can only learn in two ways. The first is as a result of its individual parts learning, and the second is by adding new members who have new knowledge. However, individual learning is not sufficient (Annabi, 2005). Individual employees must integrate their individual knowledge into organizational structures (e.g. rules, processes etc), or as the IACIS 2008 conference theme suggests, synchronize their knowledge with the organization.

The need for individuals to learn and integrate their knowledge with the organization led to a different workplace which places higher expectations on employees. Employees are expected to be prepared to make quick decisions, weeding through large amounts of information, while working in a global marketplace within a diverse workforce. Therefore, employees need to be flexible, adaptable and lifelong learners. Nevins and Stumpf (1999) echoed this sentiment in stating the need for, "self-regenerating professionals who are positioned to deal with unforeseen challenges, excel in their work and grow as quickly as their environments and responsibilities demand" (pg. 12). The resulting challenge for Information Systems (IS) programs is to prepare professionals who are adept at learning in a realworld context. It is our contention that it is no longer sufficient to produce professionals who have mastered subject matter knowledge and fundamentals. It is more important to produce professionals who are able to continually learn and master changing knowledge.

\section{The Role of IS Programs}

These challenges require both the creation of a knowledge base of the subject matter and the practice of applying this knowledge in real situations. In other words, these demands require that our students become critical thinkers, capable of "not simply the acquisition of knowledge, but the application of knowledge across time and circumstances" (VanderStoep et al. 1994). Further, our students must be adept at learning new topics and skills quickly and independently with ill defined/ambiguous structures.

Currently, there are a variety of pedagogical designs being used in IS course work. Instructors use textbooks, lectures, discussions, labs and case studies to deliver IS concepts, and theories to the students. With MIS programs' focus on the integration of people, technology in business processes, the 
development of an appropriate array IS skills is a complex task. In our experience, students often focus too much on building general systems analysis and design as well as technical skills and not enough on developing critical thinking and analytical competencies. It seems apparent that they need both. Helping our IS students reach a level of learning that enables them to critically evaluate the complexities of designing and developing information systems to solve business problems in light of relevant frameworks and theories is a primary challenge of IS courses. It is our position that textbooks, lectures, and case studies have helped students develop the needed fundamental knowledge of IS concepts and theories. Nevins and Stumpf (1999) suggest that these current methods are not sufficient given the social complexity embedded in real life settings. Additional pedagogical tools are needed to foster mastery of the skills necessary to apply these concepts and theories in the real and diverse settings of today's business environment.

The question then becomes, how do IS programs prepare students to be self-regenerating professionals? In this paper we propose that IS curricula use a constructivist philosophy of education as a guiding framework for overall program pedagogies. We chose this pedagogical approach since scholars agree that "the goal [of constructivist pedagogy] is to change the way learners think rather than increase their store of knowledge" (Pratt 2002, pg 7) a goal that coincides with ours to address the need for self-regenerating professionals (Nevins and Stumpf, 1999).

\section{LITERATURE REVIEW}

John Dewey's notion of education anchored in experience has been the debate of education scholars for many years. Many scholars agree that education, built on realistic experiences, is essential to developing critical thinkers who can compete and excel in the business environment (Kayes, 2002). Kayes (2002), Pfeffer and Fong (2002), Nevins and Stumpf, (1999) have all discussed the shortcomings of education that lack practical/clinical experience. These scholars agree that in order to produce a lasting educational outcome applicable to the workplace it is important that the students get practical experience to supplement the conceptual knowledge. In addressing this issue, they call for a variety of approaches based on different theories, but they all agree that realistic experiences that encompass social complexity followed by reflection is key to achieving learning outcomes applicable in the workplace. In his writings, McKeachie (1986, 1994, 1999) echoes these sentiments urging that course designs create maximum student involvement and reflective thinking. He viewed these as necessary to having a meaningful learning outcome.

With these issues in mind we searched the literature for theory to guide our development of IS curriculum to meet the current challenges. Our search led us to constructivist pedagogy, which is a teaching philosophy/methodology highly influenced by Piaget's constructivist theory of knowledge and learning (von Glasersfeld, 1996 in Fosnot 1996). This theory "defines knowledge as temporary, developmental, socially and culturally mediated, and thus non-objective" (Brooks and Brooks, 1993, pg. vii). Constructivism views the goal of learning to be deep understanding and conceptual development rather than skill acquisition and changes in behaviors (Fosont 1996, in Fosont 1996). Mastery here is gaining understanding, rather than gaining the set of skills predefined by instructors to be necessary in a particular subject matter. This philosophy is very fitting to IS education as it addresses the complex and constantly changing nature of IS.

The idea of this approach is that learners are continuously and actively constructing their understanding of the world around them. A learner encounters experiences with an existing knowledge structure or understanding, in this case the already developed intuitive notions and practice regarding motivation and social interaction for example. If the experience fits into the learner's knowledge structure, that structure is strengthened. On the other hand, if the experience does not fit the current understanding, the learner has to either change his or her existing structure, to fit in the new experience, or reject the new experience altogether (Pratt, 2002). This occurs through a process of "active assimilation" where the learner, with time and repetition, reaches new and higher level of understanding in order to make sense of the world around them (Black and Ammon, 1992, pg. 324). Thus "The goal [of constructivist teaching] is to change the way learners think rather than increase their store of knowledge" (Pratt 2002, pg 7). Piaget (1976) summarized the implications of this to be the notion that "understanding, not rote learning, is important in education, and to understand is to invent" (Black and Ammon, 1992, pg. 324). 
Preparing The Knowledge Worker: How Can IS Programs Meet The Challenge?

The goal of constructivist pedagogy can be accomplished through curriculum that create realistic situations where the learners can actively solve problems, interact with peers and instructors, develop their own ideas building on their preexisting knowledge structure, and focus on broad concepts rather than specific isolated skills (Brooks \& Brooks, 1993; Fosnot, 1996; Kamii \& Ewing, 1996; Buchanan and Smith 1998). More specifically, the key elements of constructivist pedagogy can be highlighted in the following five elements. Constructivist pedagogy is a:

\section{Reality rich, hands-on experience rather than book learning}

Pure lecture or book learning embodies an objectivist view of learning, following behaviorist notions, where the belief is that knowledge can be transferred in pieces to a passive learner (McKeachie, 1994). While these methods can help in acquiring important factual knowledge of the subject matter, these methods fail in linking the subject matter to the learner's knowledge structure thus failing to have a lasting effect (McKeachie, 1994). These methods fail in helping the students link the new knowledge to their own knowledge structure due to a lack of accurate and timely feedback, insufficient attention to social complexity, unrealistic time frames, insufficient practice opportunities, lack of life-like situations (especially in terms of crisis-like situations), insufficient opportunities for problemfinding and issues diagnosis, lack of use of apprenticeship or mentor-protégé relationships in the learning process, and limited linkage to students' self identities (Nevins and Stumpf 1999).

Reality rich, hands on experience, through interactivity among the student, the teacher, and the phenomena, may help students to link different concepts supplied by lectures and/or readings to their own knowledge structures by maintaining social complexity, crisis like situations, feedback, opportunities for feedback, etc... These active approaches may thus produce learning outcomes that differ from objectivist approaches to learning (McKeachie, 1994). According to cognitive theory, "knowledge learned and used in a realistic, problemsolving context is more likely to be remembered and used appropriately when needed later” (McKeachie, 1999, pg. 181). In addition, learning acquired from hands on experience can lead to a greater sense of satisfaction, motivation and development (Kayes 2002).

A constructivist instructor thus "gives learners the opportunity for concrete, contextually meaningful experience through which [learners] can search for patterns, raise their own questions, and construct their own models, concepts and strategies" based on what they already know (Fosont 1996).

\section{Social complexity rather than laboratory simplicity}

"Learning... involves acting on the world and interpreting the consequences of our actions within a personally constructed sense-making framework" (Clark, 1996). Making sense of the world around us requires that the learner's experience models real life situation including the social complexity of the workplace, especially when addressing sociotechnical issues. Rather than the sterile environment of classroom activities or the detachment of case study analysis, hands on experience that maintain the complex social elements is key. Nevins and Stumpf, (1999) highlight that educational experience should maintain the complexity of social relations and interactions as it plays an important role in decision making in real organizations and often creates crisis between organization, others and self.

Furthermore, it is important to note that the learner is an open system interacting with his or her surrounding social environment. Learning is a process that is influenced by the social relations, social structures, culture and language of the environment. Accounting for and managing that element of the learning process and its effects is a goal of constructivist pedagogy. Thus, creating a learning community, to use Clark's (2002) term, where the students are provided a safe, collaborative and encouraging environment to question and discover is key for constructivist pedagogy and can yield lasting learning outcomes used in real life situations.

\section{Change thinking patterns rather than increase store of knowledge}

Constructivist pedagogy is not merely concerned with increasing the store of knowledge or the change of behavior but by allowing the learner to reach understanding of the subject matter. By engaging the learner the goal is to gain understanding of the phenomena and change learners thinking patterns (Pratt 2002). Having the reality rich hands on experience constructivist pedagogy addresses the active nature of learners and provide them the means to take an active role in their learning. Having realistic experiences allows the learner to select stimuli that are meaningful to them. The result, of this, may be a restructuring of the learner's knowledge structure and development of a holistic 
view of the phenomenon in relation to self (Kayes 2002). This change in the knowledge structure can be reapplied in different contexts (McKeachi, 1994). Consequently, constructivist pedagogy creates relevant learning experiences that can have a long lasting effect on the thinking patterns of the learner as well as their behavior. Rather than a mere increase in isolated pieced of knowledge stored, and often later forgotten there is the opportunity for understanding, and according to Piaget (1976) "to understand is to invent” (Black and Ammon, 1992, pg. 324).

\section{Critical thinking rather than rote learning}

An even deeper goal or characteristic of constructivist pedagogy is to develop critical thinking skills in learners. Rote learning and changing knowledge structures without critically evaluating experiences is not enough. Building on the active and continuous learning nature of humans, a goal of constructivist pedagogy is to produce learners who continuously evaluate their assumptions and evaluate and question the environment around them. Furthermore, critical thinking means that one is able to reason and argue their point of view and why and how they evaluate a certain event on a particular set of criteria (Beyer, 1995). This skill is important for learners to deal with unforeseen challenges within the workplace and complexity of human behavior. This can be achieved through continuous action and reflection under the guidance and probing of instructors (McKeachi, 1999).

\section{Developmental "arc" rather than piecemeal}

Constructivism "construes learning as an interpretive, recursive, building process by active learners interacting with the physical and social world" (Fosnot 1996, pg. 30). Thus constructivist pedagogy embodies a developmental orientation to learning in which the goal is to continuously develop complex ways of thinking patterns and critical thinking skills overtime (Pratt 2002). To make sense of the world around them, learners develop and change their knowledge structures as they encounter new experiences (Clark 2002). This is a continuous and developmental process that takes place over a period of time; each experience building on its predecessors. Thus the instructor has to account for students' level of knowledge and work with them on building more complex ways of thinking over time through activities, questioning, and culmination assignments (Pratt 2002).

\section{IMPLICATIONS FOR IS CURRICULA}

While there are a variety of ways in which single courses embody constructivist pedagogy, to meet the challenge of a knowledge workplace, IS curricula as a whole can benefit by following constructivist pedagogy in creating a comprehensive and developmental learning experience. In this section we outline how an IS curriculum may embody the various elements of a constructivist pedagogy.

\section{Reality rich, hands on experience rather than book learning}

Perhaps the most important change in IS curriculum should be moving away from traditional rote learning activities to reality-rich hands-on experiences. In place of lectures and exams based on memorization, programs should include learning activities and requirements that mix conceptual and experience based activities and tests. Exams can be based on scenarios drawing on actual experience. Hands on experiences can be acquired through real client projects within course work, internships, alumni shadowing experiences, professional conferences and networking events. Through these experiences, students engage with real-world problems in complex settings. Students get to experience firsthand complexities of designing, developing and implementing technologies to solve business problems. As well, through networking events and professional conferences, students engage with professionals and develop mentoring relationships that expose them to what they will be facing once they embark on their careers.

Essential to the success of such learning experiences are faculty members that are able and willing to facilitate student learning by processing their experiences with them. Faculty must play a facilitator's role. This requires the faculty to intervene less and allow students to experiment, make mistakes and perhaps most importantly, be required to develop a position on different areas of IS. This also requires faculty to engage with business and professionals in industry in order to keep their knowledge current and create opportunities for students.

\section{Complexity rather than laboratory simplicity}

For students to truly understand the complexities of real world business problems, they must engage them in real world settings and be provided with less direction as they progress through the curriculum. As complexities come from social, technical, and political factors, it is especially difficult to introduce these elements in class settings. Real world clients and internships are a great means to introduce 
Preparing The Knowledge Worker: How Can IS Programs Meet The Challenge?

students to actual issues they will face (e.g. how selecting a software vendor may be subject to political pressures due to social relations). Faculty must allow students to struggle and fail in the process of discovering solutions. Assignments must be constructed in a way where the students identify the problems as well as the solutions.

Additionally, students must learn to integrate into professional networks and become a part of learning communities within their major, school, and profession. It is important to start the socializing process into the work environment and the profession while in the education environment and as they benefit from the coaching of capable faculty. Thus faculty have to play a role in this socialization process by providing networking opportunities.

\section{Change thinking patterns rather than increase store of knowledge}

Perhaps the main challenge of constructivist pedagogy is shifting the student and instructor roles. The student must be an active participant. To change the understanding, students must learn to relate concepts and skills to their current understanding. To do so faculty must facilitate student learning by engaging their students in real world settings. This must take place gradually. Initial courses must present business problems that students can understand and relate to their knowledge structures. The subsequent courses then have to introduce more complex problems gradually, as they shift the role and responsibility of learning onto the student.

To enact this process, there are a number of things the faculty must do. First faculty must get to know students' experiences through engagement activities such as surveys. As well, faculty must continuously challenge students' positions in order deepen their understanding. Grading in the curriculum must emphasize participation and collaboration, as this is the foundation of student engagement and learning. The ultimate goal is to transform the classroom into a learning community.

\section{Critical thinking rather than rote learning}

To ensure critical thinking it is important that the curricula include three elements of reflection: activities, self analysis, and assessment of change. Courses within the curriculum must introduce opportunities for students to reflect on their learning, how they have changed and what they need to further develop. It is not sufficient that students complete assignments without reflecting on what they have learned, how they will use what they have learned, and what they need to continue to learn. This can be accomplished through reflection assignments within each course, as well as a portfolio or reflection presentation at different milestones in the curriculum. Providing these opportunities means that faculty must provide constructive feedback and guide the planning of ongoing learning experiences. This emphasizes the importance of the faculty's role as facilitator and mentors. This is an area where alumni and senior students in the program can also engage in providing such feedback.

\section{Developmental "arc" rather than piecemeal}

As stated earlier, constructivist pedagogy embodies a developmental orientation to learning in which the goal is to continuously develop complex ways of thinking patterns and critical thinking skills overtime (Pratt 2002). This requires that the IS curriculum be developed in a way that courses are designed in the right sequence and appropriate level of integration with other courses. Each experience in the curriculum must build on its predecessors. Thus instructors must collaborate and coordinate to ensure the development of the same fundamental skills over time. This is a challenge, as we often restrict faculty and require additional time for coordination. Additionally, it is important to introduce culminating experiences in the end of the curriculum. Capstone projects, portfolios, and personal career readiness projects are excellent ways to emphasize the developmental nature of the curriculum.

\section{CONCLUSION}

Business IS programs have been criticized for their lack of ability to prepare self regenerating professionals who can continuously learn in the interest of solving ongoing complex business problems. The limitations of traditional classroom pedagogy such as lectures, discussions and simple case studies have real limits in their ability to promote skills needed to break down problems, learn new concepts, and apply understanding across evolving business situations. In this paper we proposed that IS programs organize their curriculum to be oriented towards the creation of a constructivist learning environment. Specifically, we proposed that IS programs:

- $\quad$ Create real world experiences through real client projects, internships and mentoring programs.

- Organize courses in an integrated fashion through collaboration between faculty.

- Change the role of faculty from teachers to facilitators as students progress. 
- $\quad$ Changing the role of students, giving them more responsibility in the learning process.

- Create learning environments where faculty, students, alums and industry members engage in dialogue around real world problems.

- Minimize rote learning while enhancing critical thinking.

- $\quad$ Create opportunities for reflection and individual development.

- Introducing culminating experiences at the end of the curriculum.

Implementing these recommendations presents various challenges. First, it is a challenge to provide real world experience especially in terms of clients. This adds an additional administrative task that many departments do not care to take on. Changing the role of the faculty also presents challenges. Faculty often have many responsibilities in terms of research, teaching and service. Mentoring and guiding students requires time and commitment that some departments may not be able to garner. Finally, it is important to note that evaluating learning from real world experiences is more difficult than traditional rote learning such as tests.

Despite these challenges, IS programs must gradually transform curricula to develop self-regenerating professionals. Constructivist pedagogy is an excellent vehicle to achieve this goal. Although some IS courses may already employ constructivist pedagogy, we posit that the goal should be to elevate this into the overarching philosophy which guides the ongoing development of all courses in IS curricula.

\section{REFERENCES}

Annabi, H. (2005). Moving from Individual Contribution to Group Learning: The Early Years of the Apache Web Server. . Ph.D. Dissertation thesis, Syracuse University.

Argyris C. and D. Schön, (1996). Organizational Learning II: Theory, method and practice. Reading, Mass: Addison Wesley.

Beyer, B. K. (1995). Critical thinking. Bloomington, IN: Phi Delta Kappa Educational Foundation

Black, A. \& Ammon, P. (1992). A developmentalconstructivist approach to teacher education, Journal of Teacher Education, 43(5), 323-335.

Brooks, Jacqueline Grennon, and Martin G. Brooks. 1993. In Search of Understanding: The Case for
Constructivist Classrooms. Alexandria, VA: Association for Supervision and Curriculum Development

Clark, H. (1996). Using Language. Cambridge: Cambridge University Press.

Fosnot, C. T. (1996). Constructivism: A psychological theory of learning. In C. T. Fosnot (Ed.), Constructivism: Theory, perspectives, and practice (pp. 8-33). New York, NY: Teachers College Press, Columbia University

Grant, R. M. (1996). Toward a knowledge-based theory of the firm. Strategic Management Journal, 17(Winter), 109-122.

Kamii, C., and Ewing, J. K. (1996). "Basing teaching on Piaget's constructivism." Childhood Education. 72: 260-264.

Kayes, D. (2002). Experiential learning and its critics: Preserving the role of experience in management learning and education. Academy of Management Learning and Education, 1(2): 137

McKeachie, W. J. (1986). Teaching Tips (8th ed.) Lexington, Mass: Heath.

McKeachie, W.J. (1994). Teaching tips: Strategies, research and theory for college and university teachers (9th ed.). Lexington, MA: DC Heath.

McKeachie, W.J. (1999). McKeachie’s Teaching Tips: Strategies, Research, and Theory for College and University Teachers, Tenth Edition. Boston

Nevins, M. D., and Stumpf, S. A. (1999). 21stcentury leadership: Redefining management education. Strategy and Business, Third Quarter: 41-51

Pfeffer, J. and Fong, C. (2002) The end of business schools? Less success than meets the eye. Academy of Management Learning and Education 1(2): 78-95.

Piaget, J. (1976). Piaget sampler: An introduction to Jean Piaget through his own words. New York: Wiley.

Pratt, D. D. (2002). Good teaching: one size fits all? In An Up-date on Teaching Theory, Jovita RossGordon (Ed.), San Francisco: Jossey-Bass, Publishers. 
Preparing The Knowledge Worker: How Can IS Programs Meet The Challenge?

Simon, H. A. (1991). Bounded Rationality and Organizational Learning. Organization Science, 2, 125-134.

VanderStoep, S.W., \& Anderman, E., \& Midgley, C. (1994). The relationship among principal 'venturesomeness,' a stress on excellence, and the personal engagement of teachers and students.
School Effectiveness and School Improvement, 5, 254-271.

von Glasersfeld, E. (1996).Introduction: Aspects of constructivism. In C. Fosnot (Ed.),

Constructivism: Theory, perspectives, and practice, (pp.3-7). New York: Teachers College Press. 